\title{
Rectangular Shaped Microstrip Antenna for Triple-band Operation
}

\author{
PreetKanwal Kaur ${ }^{1}$, Ramanjeet Singh ${ }^{2}$ \\ M.Tech Student, ECE, Ludhiana College of Engineering and Technology,Ludhiana, Punjab, India ${ }^{1}$ \\ Assistant Professor, ECE, Ludhiana College of Engineering and Technology, Ludhiana, Punjab, India ${ }^{2}$
}

\begin{abstract}
In this paper, a rectangular microstrip patch antenna for multiband operation is designed and simulated. The proposed geometry of antenna covers three frequency bands and can be used for different wireless applications. The designed antenna has simple shape of rectangular patch with a co-axial feed. The performance parameters for proposed rectangular multislot antenna such as return loss, gain, directivity, bandwidth, VSWR are studied. The proposed antenna shows maximum gain up to $6.69 \mathrm{dBi}$, bandwidth above $108 \mathrm{MHz}$, and maximum directivity of $10.53 \mathrm{dBi}$. IE3D (Integral Equation in Three Dimensions) software has been used for design and simulation of proposed antennas.
\end{abstract}

Keywords: Microstrip, Patch, Triple-band, Slots, IE3D, Wireless Applications

\section{INTRODUCTION}

Microstrippatchantennas are widely used because of their advantages. Microstrip patch antennas have been studied extensively due to their attractive characteristics of low profile, light weight, robustness and ease of fabrication [1]. Multi-band antennas are of interest in many wireless applications that use different frequency bands by avoiding the use of separate antenna. Dual or multi-frequency operations are common in Radar and Satellite communications. Therefore, microstrip slot antenna has been intensively studied and various slot shapes with different performance have been developed [2].

Number of techniques can be used to make a multiband antenna. Slot technique is used to increase the number of operating frequency bands. In order to obtain six frequency bands, microstrip patch is combined with slot antenna. Slots are positioned at ground plane under the patch [3]. A stacked rectangular microstrip antenna with a shorting plate is combined with a stacked rectangular ring microstrip antenna for triple-band operation in ITS. This antenna is fed with L-probe feed [4]. By loading a pair of right-angle slots and a modified U-shaped slot in a rectangular microstrip patch, antenna bandwidth is enhanced with good radiating characteristics [5].

A half-U-slot-cut and rectangular-slot-cut are used in rectangular microstrip antenna to increase gain and bandwidth of antenna [6].The reverse L-shaped slot is connected from bottom of rectangular slot, by combining both the structures with a strip and u-shaped slot three frequency bands can be obtained [7]. Other than rectangular shape, a single layer triangle shaped planar antenna is used for multiband operation [8]. A dual band circular microstrip slot antenna consists of an offset microstrip-fed line with strip inserted closed to radiating edges of slot [9].

In this paper, slotting of the rectangular patch antenna is done to achieve multiband operation. This rectangular patch antenna has multi-slots at appropriate places to achievemultiple independent frequency bands. By proper

selection of slot size, feed and tuning their dimensions multiple frequency bands can be achieved. The antenna is designed on RT duroid substrate and simulated on IE3D software by Zealand.

\section{Antenna Specifications}

The rectangular shape has taken as base shape of the proposed antenna. RT Duroid material has been used as substrate having thickness $3.175 \mathrm{~mm}$. The dielectric constant of the substrate is 2.2 and the loss tangent has been taken as 0.0009.Fig.1 show rectangular patch antenna.

Dimensions of rectangular patch are calculated for $2.4 \mathrm{GHz}$ frequency. Co-axial feed is used for feeding the antenna. The rectangular patch antenna having length is $40.35 \mathrm{~mm}$ and width is $49.41 \mathrm{~mm}$.

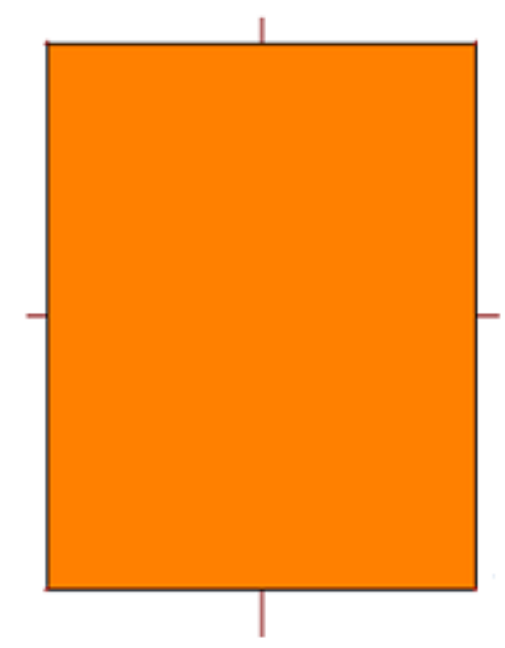

Fig.1Rectangular Patch Antenna

For triple-band operation, slots are to be etched in the rectangular patch of proposed antenna. Three slots of rectangular shape are etched to achieve multiple frequency bands. Fig. 2 shows proposedmultislot antenna. 


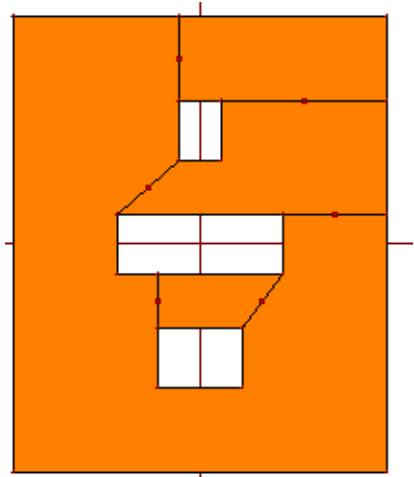

Fig.2 Multislot Antenna

\section{III.RESULTS AND DISCUSSION}

Return loss characteristics, elevation and azimuthal pattern gain display, directivity, and VSWR are shown in respective figures. Return loss versus frequency plot is shown in Fig. 3. The return loss value describes the reduction in the amplitude of the reflected energy, as compared to the forward energy. The resonating frequencies are observed according to $-10 \mathrm{~dB}$ return loss. Firstly, simulation results of rectangular patch antenna are shown.

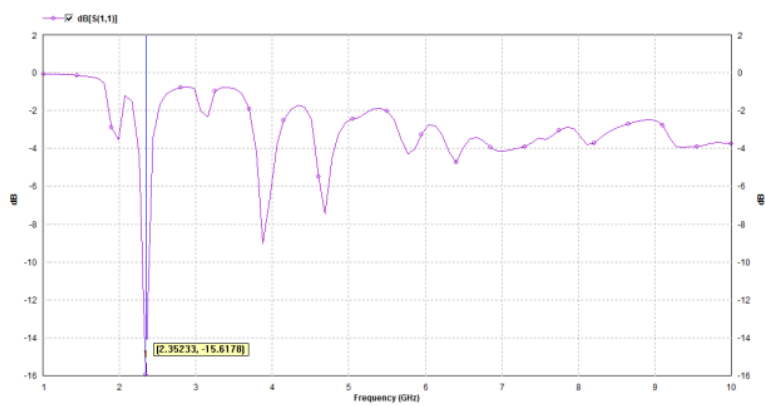

Fig.3 Return Loss of Rectangular Antenna

Return loss characteristics show that the resonant frequency is $2.35 \mathrm{GHz}$. At this frequency the return loss is less than $-15.61 \mathrm{~dB}$.It has bandwidth of $82 \mathrm{MHz}$ at $2.35 \mathrm{GHz}$ frequency.

Two dimensional radiation patterns of rectangular patch antenna are defined in terms of elevation pattern gain display and azimuthal pattern gain display. The radiation patterns of an antenna provide the information that describes how the antenna directs the energy it radiates. The maximum achievable gain at $2.35 \mathrm{GHz}$ is $6.87 \mathrm{dBi}$ is displayed in Fig. 4 and 5.

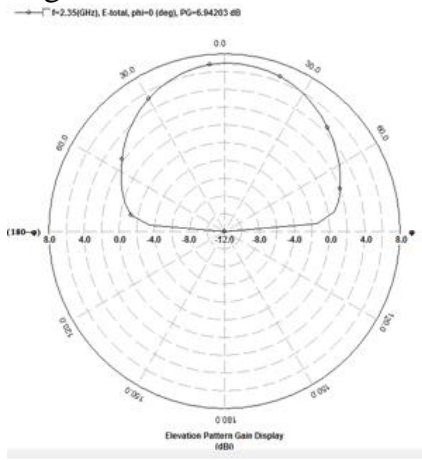

Fig.4 Elevation Pattern Display of Rectangular Patch Antenna

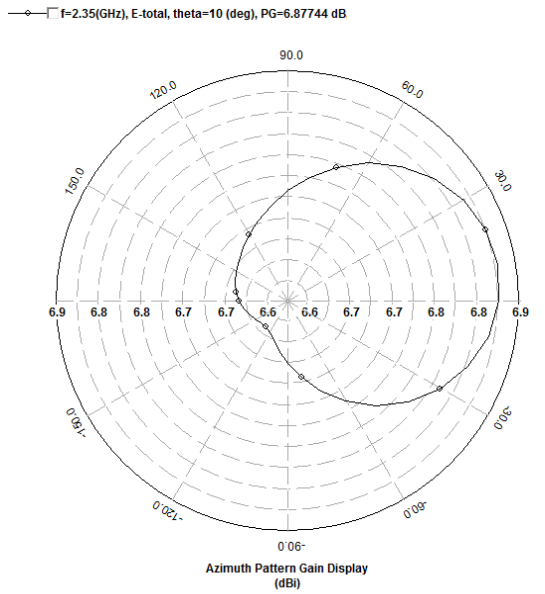

Fig.5 Azimuthal Pattern Display of Rectangular Patch Antenna

Directivity is ameasure of how directional radiationpattern is.Fig. 6 showsdirectivity versus frequency plot. The maximum directivity is $7.75 \mathrm{dBi}$ for rectangular patch antenna at resonant frequency $2.35 \mathrm{GHz}$.

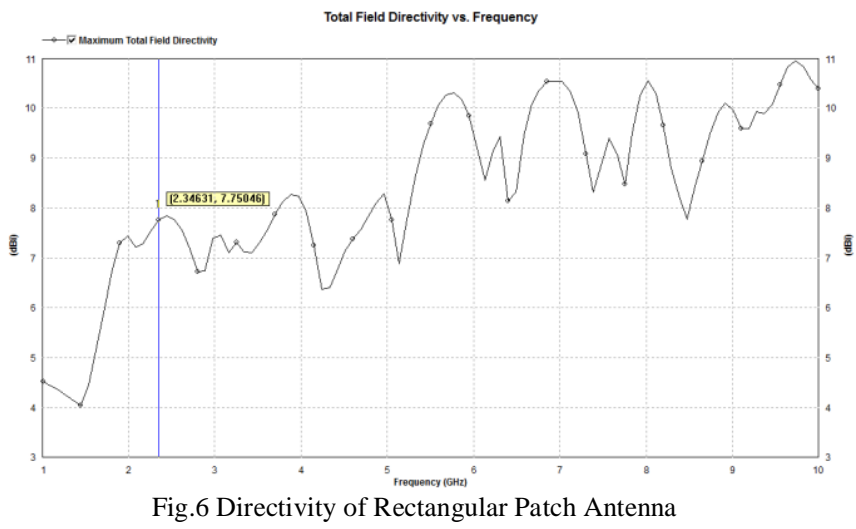

InFig.7 VSWR (Voltage Standing Wave Ratio) versus frequency is shown. The rectangular patch antenna having VSWR value 1.60 is shown.

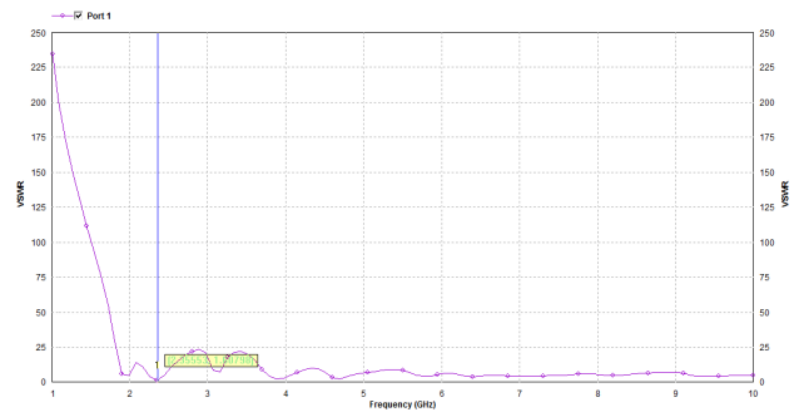

Fig.7VSWR of Rectangular Patch Antenna

Now, simulation results of multislot antenna are discussed. Fig. 8 shows the return loss of proposedmultislot antenna. From this figure it can be find that the antenna resonates at three different resonant frequencies $5.41 \mathrm{GHz}, 6.31 \mathrm{GHz}$ and $7.29 \mathrm{GHz}$ and the return loss at these resonant frequencies is $-24.51 \mathrm{dBi}, \quad-10.79 \mathrm{dBi}$ and $-17.56 \mathrm{dBi}$ respectively. At resonant frequencies of $5.4 \mathrm{GHz}, 6.31 \mathrm{GHz}$ and $7.29 \mathrm{GHz}$ multislot antenna has bandwidth of $331 \mathrm{MHz}, 108 \mathrm{MHz}$ and $313 \mathrm{MHz}$. 


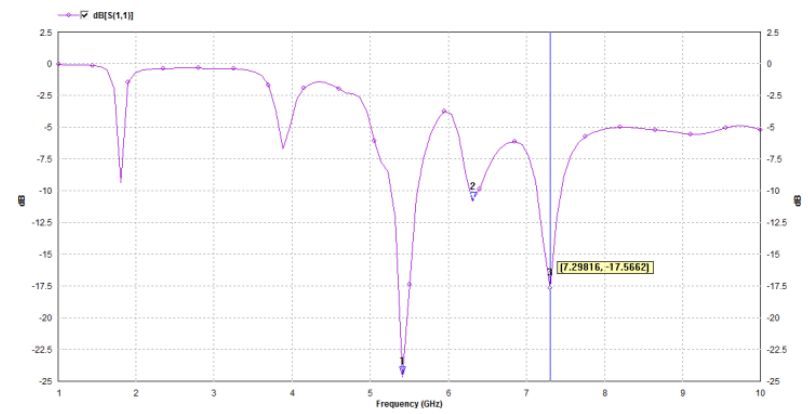

Fig.8Return Loss of Multislot Antenna

The elevation pattern gain display and azimuthal pattern gain display of multislot antenna are shown in Fig. 9 and 10.

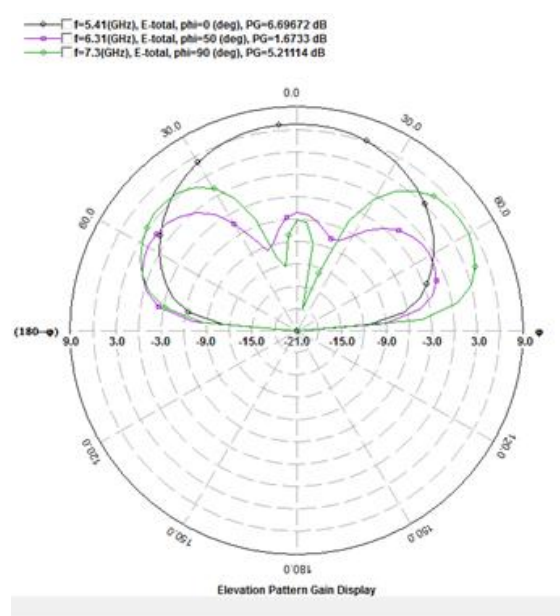

Fig.9 Elevation Pattern Display of Multislot Antenna

The maximum achievable gain at these frequencies is $5.4 \mathrm{GHz}, 6.31 \mathrm{GHz}$ and $7.29 \mathrm{GHz}$ is $6.69 \mathrm{dBi}, 1.67 \mathrm{dBi}$, and 5.21dBi shown in Fig. 9 and 10.

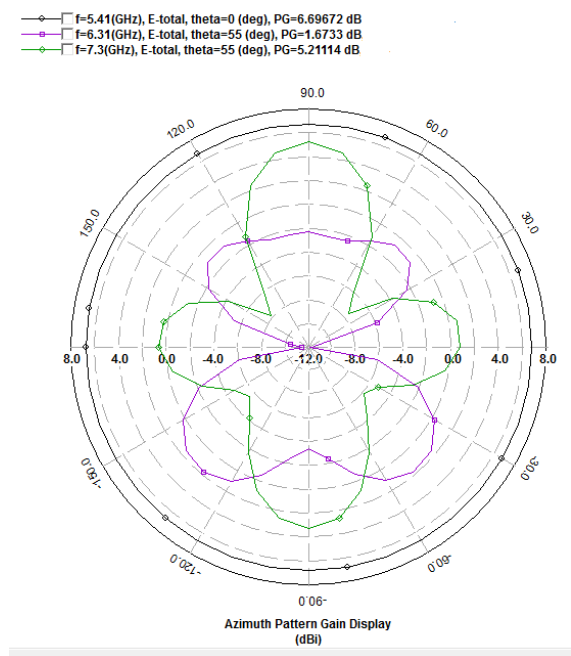

Fig.10. Azimuthal Pattern Display of Multislot Antenna

Fig.11 shows the maximum directivity of $10.53 \mathrm{dBi}$, $8.63 \mathrm{dBi}$ and $10.45 \mathrm{dBi}$ for multislot antenna at resonant frequencies of $5.41 \mathrm{GHz}, \quad 6.31 \mathrm{GHz}$ and $7.29 \mathrm{GHz}$ respectively

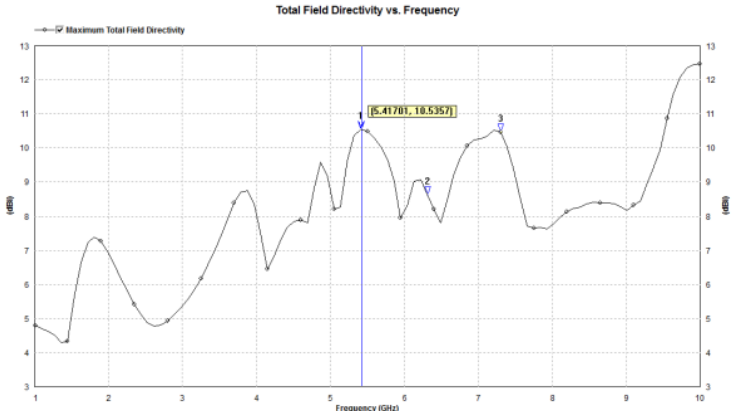

Fig.11. Directivity of Multislot Antenna

VSWRhaving value 1.13 at $5.41 \mathrm{GHz}, 1.81$ at $6.31 \mathrm{GHz}$ and 1.30 at $7.29 \mathrm{GHz}$ of frequency as shown in Fig. 12 .

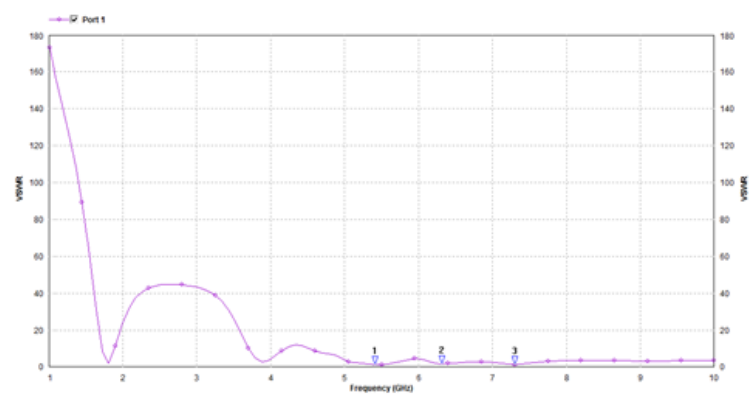

Fig.12.VSWR of Multislot Antenna

Comparison of performance parameters of rectangular patch antenna and multislot antenna is given in Table 1. Proposed antenna shows three frequencies for triple band operation with good performance of parameters.

TABLE 1

COMPARISONOF VARIOUS ANTENNA PARAMETERS

\begin{tabular}{|c|c|c|c|c|}
\hline Parameters & $\begin{array}{c}\text { Rectangular } \\
\text { Patch } \\
\text { Antenna }\end{array}$ & \multicolumn{3}{|c|}{ Multislot Antenna } \\
\hline $\begin{array}{c}\text { Resonant } \\
\text { Frequency }\end{array}$ & $2.35 \mathrm{GHz}$ & $5.41 \mathrm{GHz}$ & $6.31 \mathrm{GHz}$ & $7.29 \mathrm{GHz}$ \\
\hline Return Loss & $-15.61 \mathrm{~dB}$ & $-24.51 \mathrm{~dB}$ & $-10.79 \mathrm{~dB}$ & $-17.56 \mathrm{~dB}$ \\
\hline Gain & $6.87 \mathrm{dBi}$ & $6.69 \mathrm{dBi}$ & $1.67 \mathrm{dBi}$ & $5.21 \mathrm{dBi}$ \\
\hline Bandwidth & $82 \mathrm{MHz}$ & $331 \mathrm{MHz}$ & $108 \mathrm{MHz}$ & $313 \mathrm{MHz}$ \\
\hline Directivity & $7.75 \mathrm{dBi}$ & $10.53 \mathrm{dBi}$ & $8.63 \mathrm{dBi}$ & $10.45 \mathrm{dBi}$ \\
\hline VSWR & 1.60 & 1.13 & 1.81 & 1.30 \\
\hline
\end{tabular}

\section{IV.CONCLUSION}

In this paper, rectangular patch antenna and multislot antenna are discussed in detail. The proposed multislotantenna resonates at three different frequencies $5.41 \mathrm{GHz}, 6.31 \mathrm{GHz}$ and $7.29 \mathrm{GHz}$ with suitable antenna parameters. This means multiband antenna can be designed with the help of slotting. This multislot antenna can be used as triple-band antenna in various wireless applications like Wi-Fi, Radar, and UWB applications.

\section{ACKNOWLEDGMENT}

The authors appreciatively acknowledge the support to bring out this study and work from Electronic and CommunicationEngineering department of Ludhiana Institute of Engineering and Technology, Ludhiana, Punjab, India 


\section{REFERENCES}

[1] R.K. Vishwakarma, "Design of rectangular stacked microstrip antenna for dual-band",International Conference on Emerging Trends in Electronic and Photonic Devices \& Systems (ELECTRO2009), pp. 328-331,2009

[2] A.A.NOvi, N.Saha, S.Dey, and N.N. Alam "Symmetrical slot loaded dual band elliptical microstrip patch antenna", PIERS Proceedings, Moscow, Russia, pp.538-541, August 2012

[3] H.A. Majid,M. K.A. Rahim, M.R. Hamid, M.F.Ismail,"Frequency reconfigurable microstrip patch slot antenna with directional radiation pattern”, Progress In Electromagnetics Research,2014vol. 144, pp.319-328

[4] T.Fujimoto, R.Nakanishi, "Stackedrectangularmicrostrip antenna for triple band (GPS/VICS/ETC) operation in ITS" Antennas and Propagation Society International Symposium, pp. 175-178,2011

[5] J.Y.Sze,K.L. Wong, "Slotted rectangular microstrip antenna for bandwidth enhancement" IEEE Transactions on Antennas and Propagation, August 2000,Vol. 48, No. 8, pp.1194-1152

[6] A.A. Deshmukh, and K. P. Ray, "Compact Broadband Slotted Rectangular Microstrip Antenna" IEEE Antennas and Wireless Propagation Letters,2009 Vol. 8, 1410-1413

[7] W.S.Chen, B.Y.Lee, P.Y. Chang, "A compact microstrip -line-fed slot antenna with dual -band notched for Wimax operation", Progress In Electromagnetics Research,2010,vol. 16,pp. 13-23

[8] Y. Song, Y.-C Jiao, G. Zhao, F.S. Zhang, "Multiband CPW feed triangle shaped monopole antenna for wireless applications." Progress In Electromagnetics Research, 2007 vol.70, pp. 329-336

[9] J. J. Tiang,M. T. Islam, N. Misran, and J. S. Mandeep, "Circular microstrip slot antenna for dual frequency RFID application", Progress In Electromagnetics Research , 2011vol. 120,pp.500-510 